\title{
Normal Phenolsulfonphthalein Test
}

National Cancer Institute

\section{Source}

National Cancer Institute. Normal Phenolsulfonphthalein Test. NCI Thesaurus. Code C35657.

A laboratory test result indicating normal parameters after a phenolsulfonphthaliein test. 